\title{
The Surface of Mars
}

\section{South Polar Cap}

\author{
Robert P. Sharp, Bruce C. Murray, Robert B. Leighton, \\ Laurence A. Soderblom and James A. Cutts \\ Division of Geological Sciences and Division of Physics, Mathematics and Astronomy \\ California Institute of Technology, Pasadena 91109
}

\begin{abstract}
The south polar cap of Mars occupies a region of cratered terrain. Immediately outside the shrinking cap craters appear no more modified than those in areas farther north that are not annually frost covered. Craters showing through the frost mantle are locally as abundant as elsewhere on Mars. Only in a central region close to the pole are craters sparse. Both far- and near-encounter views reveal a highly irregular pole-cap edge. Photos of the same sector taken six days apart are near duplicates, suggesting that the irregularity is primarily ground controlled. No evidence of the classical polar collar is seen. Within the marginal zone, frost is preserved largely in crater bottoms and on slopes inclined away from the sun. Preferential retention in low spots supports the earlier suggestion that the Mountains of Mitchel may actually be depressions. An argument based on insolation as the prime factor in frost wastage and the narrow width of the marginal zone suggests that slopes of topographic features therein are mostly gentle, on the order of a few degrees. The frost cover of the pole-cap interior may range widely in thickness, obscuring parts of some craters and seemingly enhancing topographic visibility elsewhere, possibly through variations in thickness and reflectivity. Unusually bright areas on the cap surface, and differences in luminance between bright rims and the more somber floors of craters and other depressions, may be due in large part to differences in related frost textures and to the local history of evaporation and sublimation. Irregularly angular depressions within the polecap frost termed 'etch pits' may be the product of differential ablation or the undermining by wind of a slabby surficial crust. Encircling the south pole is a region of subdued relief with a paucity of craters, which displays enigmatic quasi-linear markings believed to be ground features. Although no satisfactory explanation of these markings has been formulated, it seems likely that this region has been occupied repeatedly by perennial masses of $\mathrm{CO}_{2}$ ice, formed and maintained during those phases of the martian precessional cycle that resulted in short cool summers in the southern hemisphere. Such ice masses may play a role in producing the unusual features of the central polar region. Physical relationships suggest a local maximum frost thickness as great as tens of meters. The possibility should be kept in mind that remnants of perennial $\mathrm{CO}_{2}$ ice of still greater thickness may exist locally, for example, in the 'etch pit' area.
\end{abstract}

The south polar cap of Mars was first seen by man more than 300 years ago, and its annual waxing and waning phases have been observed for over 200 years by earth-based optical astronomers [Slipher, 1962]. In 1969 Mariners 6 and 7, through numerous far-encounter photographs (Figures 1 and 2), and Mariner 7, through ten near-encounter frames (Figure 3), gave the closest and most satisfying views of this Martian feature.

The characteristic physical features and

${ }^{1}$ Contribution 1893, Division of Geological Sciences, California Institute of Technology, Pasadena 91109.

Copyright (c) 1971 by the American Geophysical Union. relationships of the polar cap as revealed in these photos are described. Implications of these observations with respect to the physical nature, distribution, thickness, and behavior of the pole-cap frost are examined. The origin of features seemingly unique to the cap is explored.

The near-encounter photomosaic (Figure 3) is one of the more informative and striking products of the Mariner $1969 \mathrm{TV}$ experiment. This near-encounter polar cap photography involved an in-flight reprogramming of the on-board computer directing a slue of the instrument platform to afford the science systems a view of the polar cap.

Locations of features or areas on polar-region photos are more effectively expressed in terms 
of right or left than east or west. Therefore readers referring to individual photos in this section should make sure that the orientation is consistent with that of the corresponding photo in the mosaics (Figures 3 and 4).

\section{Far-Encounter Vitiws}

Far-encounter frames show parts of the pole-cap edge and interior not covered by nearencounter photos, as well as the regional configurations of the pole-cap margin, and they also record possible temporal variations in frost cover, associated atmospheric phenomena, or photometric functions.

Far-encounter pictures show considerable irregularity in the pole-cap edge on a $50-200 \mathrm{~km}$ scale. The relief of underlying cratered terrain is clearly one cause, and other topographic relief is inferred to play a part. Craters exceeding 100 $\mathrm{km}$ in diameter are visible just within the polecap margin on frames taken from distances in excess of $500,000 \mathrm{~km}$ (6F36, Figure 1).

All far-encounter views of the polar cap show fuzziness and lack of definition toward the morning terminator on the west; compare the east and west edges of the planetary disc (Figures 1 and 2). A localized morning haze might account for this fuzziness and for the limb darkening over the polar cap appearing principally on its morning side. However, Leovy et al. [1971] suggest that the limb darkening is due to a photometric function of the planetary surface and not to a general atmospheric haze.

Comparison of successive views (Figure 1) suggests that changes in the size, shape, and density of irregular, wispy projections from the pole-cap edge may occur from hour to hour. However, photos taken 1 min apart (Figure 2) show differences about as great, and pairs of views of corresponding sectors of the pole-cap margin taken six days apart show no greater changes (Figure 2). This suggests that the seeming variations may be the product of differences in lighting, viewing angles, and instrumental response. Indeed, six-day photo pairs show a consistency in pole-cap edge configuration that hardly seems compatible with anything as ephemeral as clouds or mist, unless they are strongly controlled by ground features.

The interior of the cap displays an irregular mottling involving modest differences in albedo over areas of various shapes and sizes up to $300 \mathrm{~km}$ across. Individual features appear at fixed positions and with corresponding size and shape on successive far-encounter frames (Figure 1) taken about $60 \mathrm{~min}$ apart. These features presumably represent real differences in reflectivity on the cap's surface or a difference in the atmosphere over it.

\section{Near-Encounter Views}

Near-encounter views of the polar cap were taken from spacecraft positions north of $45^{\circ} \mathrm{S}$, so that obliquity is high $\left(40^{\circ}-48^{\circ}\right.$ from vertical), and slant distances were large $(4925-6340 \mathrm{~km})$.

\section{Features of the Marginal Zone}

Treatment of the pole-cap margin is facilitated by division into three parts: the extramarginal area, the outer marginal zone, and the inner marginal zone. These areas are transitory, moving inward with the shrinking cap. Along the $330^{\circ}$ longitude line (Figure 4), the extramarginal area extends south to $57^{\circ} \mathrm{S}$, the outer marginal zone lies between $57^{\circ}$ and $58.5^{\circ}$, and the inner marginal zone is between $58.5^{\circ}$ and $60.5^{\circ}$.

Extramarginal area. This area comprises the bare ground immediately beyond the outer limit of recognizable frost patches at the time of viewing (earth date, August 5, 1969) but lying within the region covered each year by the extended polar cap. Most of the extramarginal area displays craters (7N11, 7N13, Figure 3) seemingly comparable in abundance and character to other well-cratered regions on Mars. However, the western third of $7 \mathrm{~N} 11$ seems devoid of craters. Whether this area is truly featureless, as suggested by $\mathrm{B}$ frame $7 \mathrm{~N} 10$, or is simply obscured by local clouds or haze is not known. The possibility of a localized haze is supported by a light patch at this location on a trueintensity version of $7 \mathrm{~N} 11$ (Figure 4), although Leovy et al. [1971] suggest that this lightness could be the product of a surface photometric function sensitive to the solar incident angle.

The remainder of the extramarginal zone visible on $7 \mathrm{~N} 11$ and $7 \mathrm{~N} 13$ (Figure 3 ) exhibits craters seemingly no different from craters farther north along the Mariner 7 path outside the area of annual pole-cap coverage $(7 \mathrm{~N} 9$, 7N7). No unusual topographic forms are seen in the extramarginal zone. 

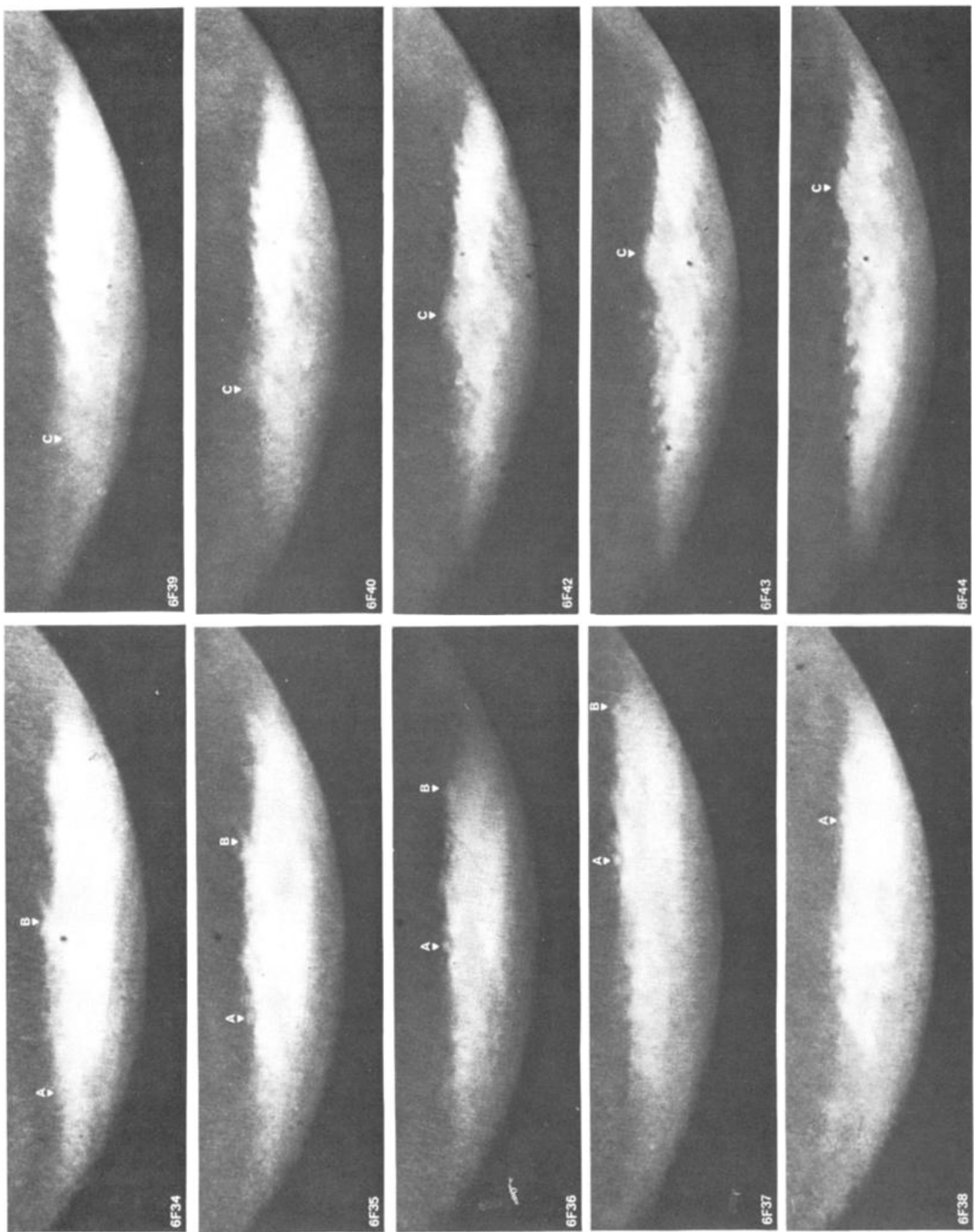

Fig. 1. Mariner 6 far-encounter views of south polar cap, enlarged to a common scale. Each successive frame represents an elapsed time ranging between 56 and 65 minutes and a plantetary rotation between $14^{\circ}$ and $16^{\circ}$. Crater at $\mathrm{A}$ in $6 \mathrm{~F} 37$ about $110 \mathrm{~km}$ across. Small dark spots are geometric reference marks on vidicon tube. $\mathrm{A}, \mathrm{B}$, and $\mathrm{C}$ are simply marginal irregularities selected as reference points. Approximate longitudes: A, $209^{\circ} \mathrm{E} ; \mathrm{B}, 240^{\circ} \mathrm{E} ; \mathrm{C}, 133^{\circ} \mathrm{E}$. 
Outer marginal zone. This zone is characterized by preservation of disconnected frost patches. In maximum discriminable photo versions (Figure 3) it lies within a spurious dark band produced by an automatic gain control (AGC) in the spacecraft photographic system. As the scan trace in the TV system passed off the cap, slow response of the AGC to the great contrast produced a black band in the photos. This is an artifact of the system and not the classical polar collar. Photo versions from which the AGC effect is removed (Figure 4) show no suggestion of a polar collar at the time of Mariner 7 flyby but are not absolute proof that such a collar is lacking.

Within the outer marginal zone, frost is preserved in crater bottoms, in other presumed low spots, and on slopes inclined away from the sun. Craters with a complete frost cover on their floor appear as solid elliptical white spots, others with only fractional floor coverings appear as irregular white areas, and some with frost only on south-facing inner walls appear as white crescents concave southward. Craters on B frame $7 \mathrm{~N} 12$ within this zone are grotesquely distorted by the combination of low lighting $\left(37^{\circ}\right)$ and the enhancement of localized frost. Ground relief is also emphasized, making the surface appear rougher than elsewhere on Mars.
The outer marginal zone displays some scattered, irregular, dense, white patches (see right center, $7 \mathrm{~N} 11$ ), suggestive of optically thick clouds. However, these patches do not display shadows or have the outlines or structures normally expected of uplifted or convective clouds [Leovy et al., 1971]. The patches may represent unusual accumulations of frost associated with irregular topographic features.

Inner marginal zone. In this zone the frost cover, although irregular and ragged at its outer edge, is essentially continuous except for islands of frost-free or nearly frost-free ground. These islands register nearly black because of a threefold contrast enhancement in the TV system.

Craters seem more abundant than in most of the polar cap area because of accentuation by the irregularly distributed frost. Many appear as dark-line ellipses, owing to obliquity of view, or as solid dark crescents concave north. Both forms stand out against the prevailing white background. Some craters display a black dot within a central white area that could be a bare spot atop a central peak.

\section{Polar-Cap Interior}

In terms of area, this is the largest pole-cap subdivision. It has an essentially continuous
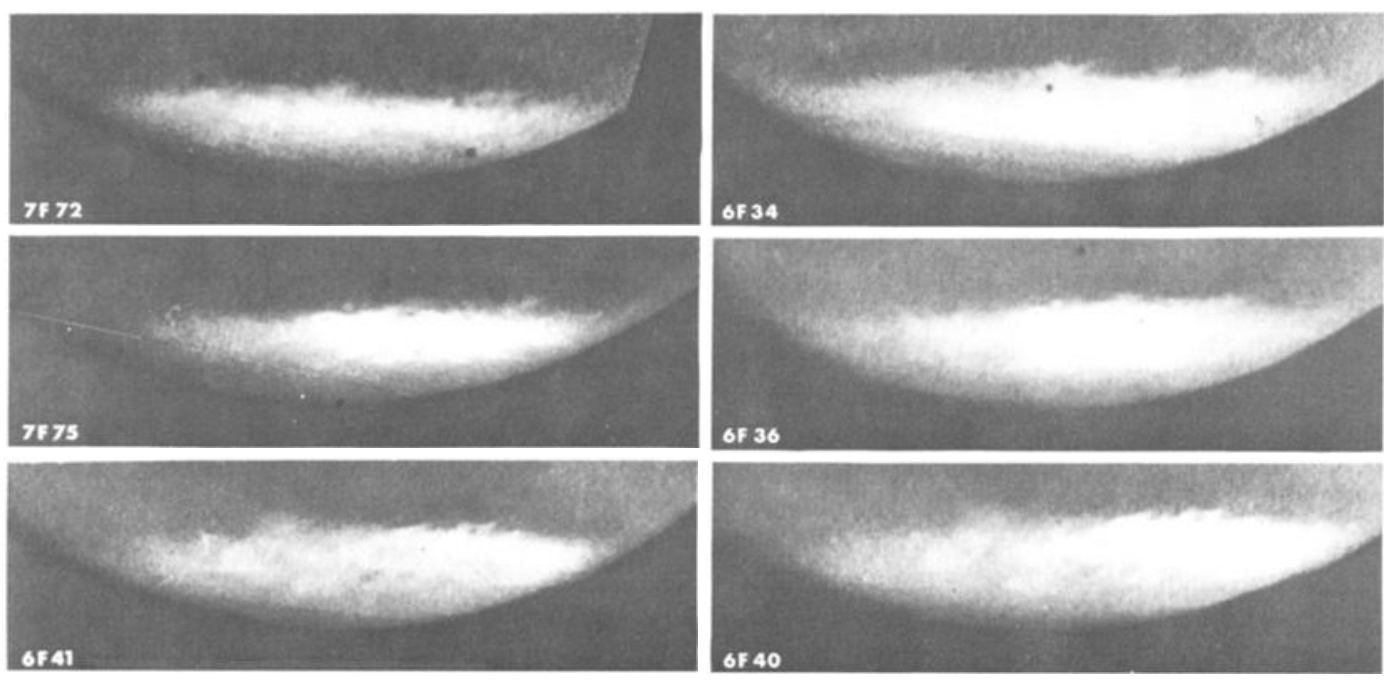

Fig. 2. Comparative far-encounter views of south polar cap. 7F72 and 7F75 each taken 6 days after $6 \mathrm{~F} 34$ and $6 \mathrm{~F} 36$, but $6 \mathrm{~F} 41$ and $6 \mathrm{~F} 40$ taken only one minute apart. Central longitudes: $7 \mathrm{~F} 72,244^{\circ} \mathrm{E} ; 7 \mathrm{~F} 75,210^{\circ} \mathrm{E} ; 6 \mathrm{~F} 41,146^{\circ} \mathrm{E}$. Mariner 7 camera system yielded sharper contrast. 


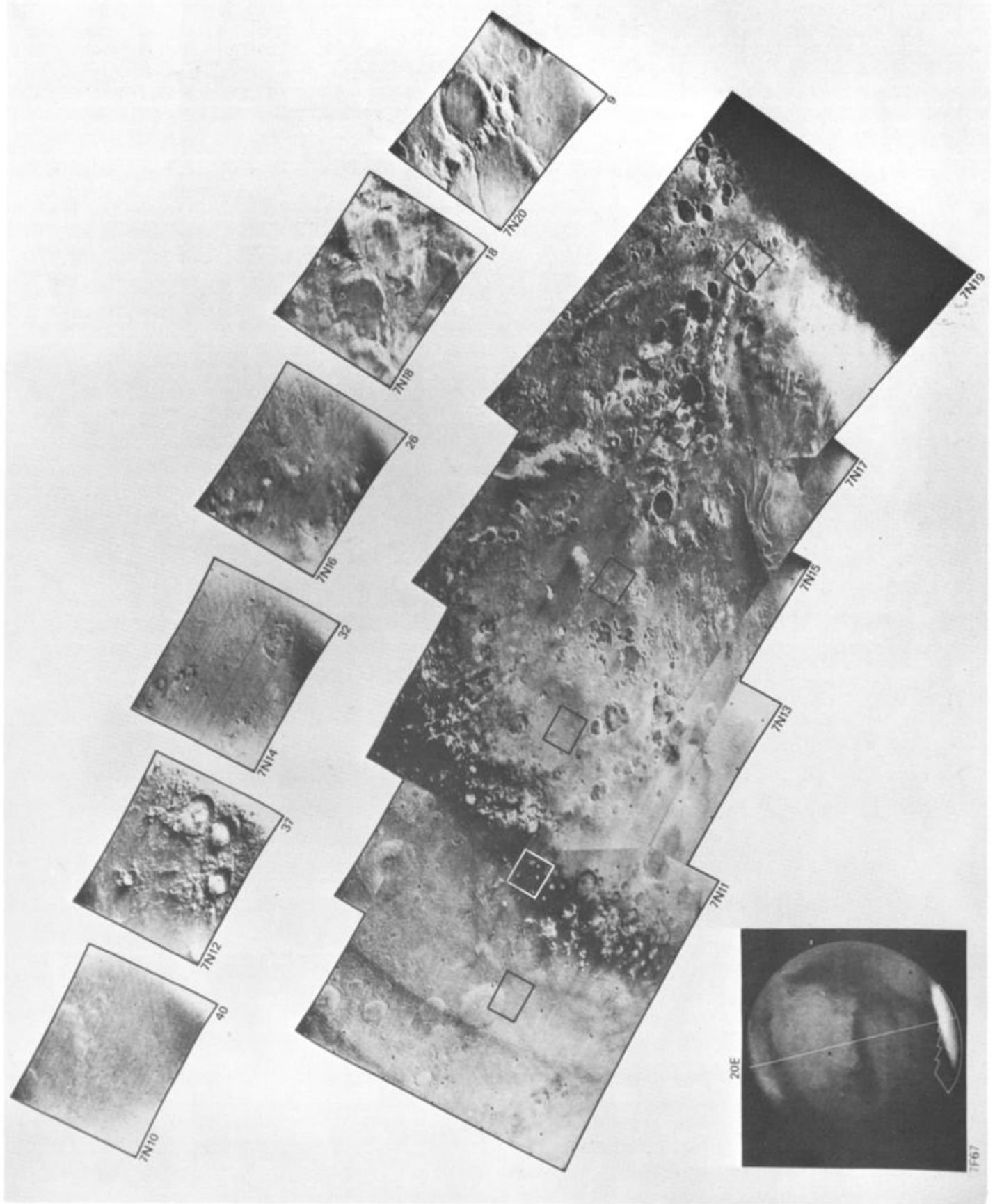

Fig. 3. Mosaic of maximum discriminable near-encounter photos of south polar cap. Location of B frames indicated by black inset rectangles; sun elevation above horizon at lower right corner of B-frames. Latitude-longitude grid given on Figure 4. Location of mosaic shown on far-encounter inset. 


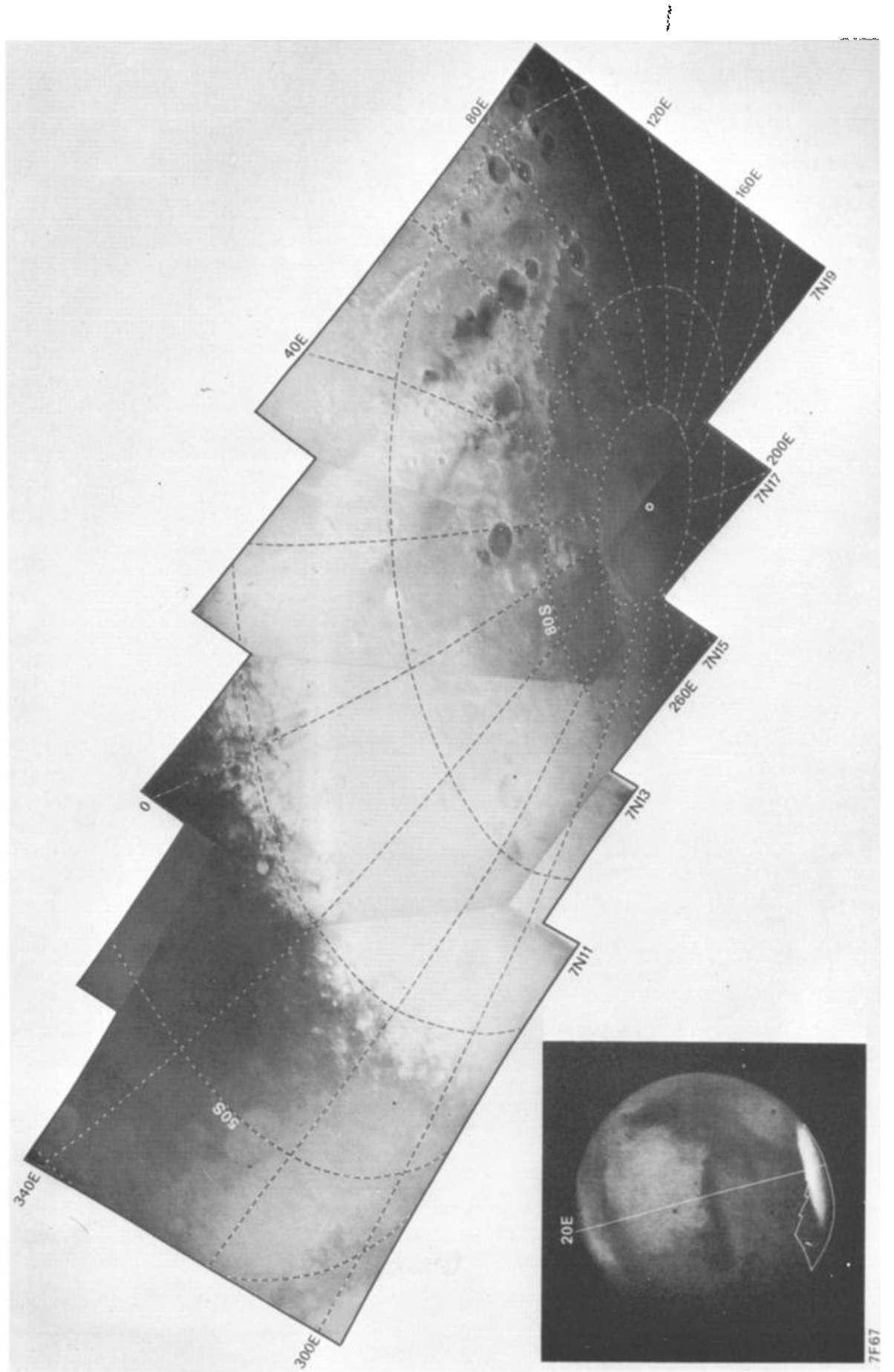

Fig. 4. True-intensity mosaic, without automatic gain control, south polar cap. Compare Figure 3. 
frost cover, an abundance of craters, and a variety of other topographic features.

Most craters of the polar-cap interior display bright rims and somber floors. The floors are not frost free, for they do not match the blackness of bare ground at the pole-cap margin. The intercrater surface is lighter than crater floors but not as bright as crater rims.

Outlines of larger craters appear irregular and ragged compared to unfrosted craters. Extending outward from a few medium-sized craters (see upper center $7 \mathrm{~N} 19$ ) is a radial pattern of short ridges and furrows. Some craters show small white central dots.

Craters larger than $15 \mathrm{~km}$ appear to be flat floored, but many smaller craters are bowl shaped. A number, even with flat floors and diameters of $30-50 \mathrm{~km}$, have distinct rims. A part of some craters is obscured, although the remainder is clearly visible, a phenomenon not common to craters elsewhere on Mars. In the upper right corner of $7 \mathrm{~N} 19$, craters are as numerous as in the most heavily cratered Martian areas.

The pole-cap interior displays features not observed elsewhere. Most unusual are irregular depressions here termed 'etch pits' for descriptive purposes. Elongated forms of similar character are termed 'etch furrows.' 'Etch' features are best shown in the center of $7 \mathrm{~N} 15$. Like craters, etch pits have lighter rims and darker floors, but unlike craters they are irregularly angular in outline. Vertical relief is not yet known, but more quantitative evaluation of slopes and heights may be possible with advanced data processing. The 'elephant's footprint' (lower right of $7 \mathrm{~N} 14$ ), judging from its low relief, may be a frost-filled crater with shallow etch pits.

South of the principal area of etch features is a series of short, parallel linear features aligned in a WNW direction, herein termed beaded lineations from the tiny nodes they connect (Figure 5). Less regular lineations of several trends are seen in other parts of the pole-cap interior. The pole-cap interior displays a number of small subdued features of positive relief (see $7 \mathrm{~N} 14$ for examples).

A frame $7 \mathrm{~N} 19$ shows several noteworthy features. In the upper center part at about $72^{\circ} \mathrm{S}, 55^{\circ} \mathrm{E}$ (also in upper right corner of $7 \mathrm{~N} 17$ and Figure 5) is a crater, roughly $15 \mathrm{~km}$ across, nearly surrounded by an irregularly outlined feature of positive relief that looks like a pile of volcanic flows extruded from a central vent. However, the crater is larger than most terrestrial central vents, and the surrounding relief might be the product of etching. Roughly $250 \mathrm{~km}$ to the west is a belt featuring a number of short

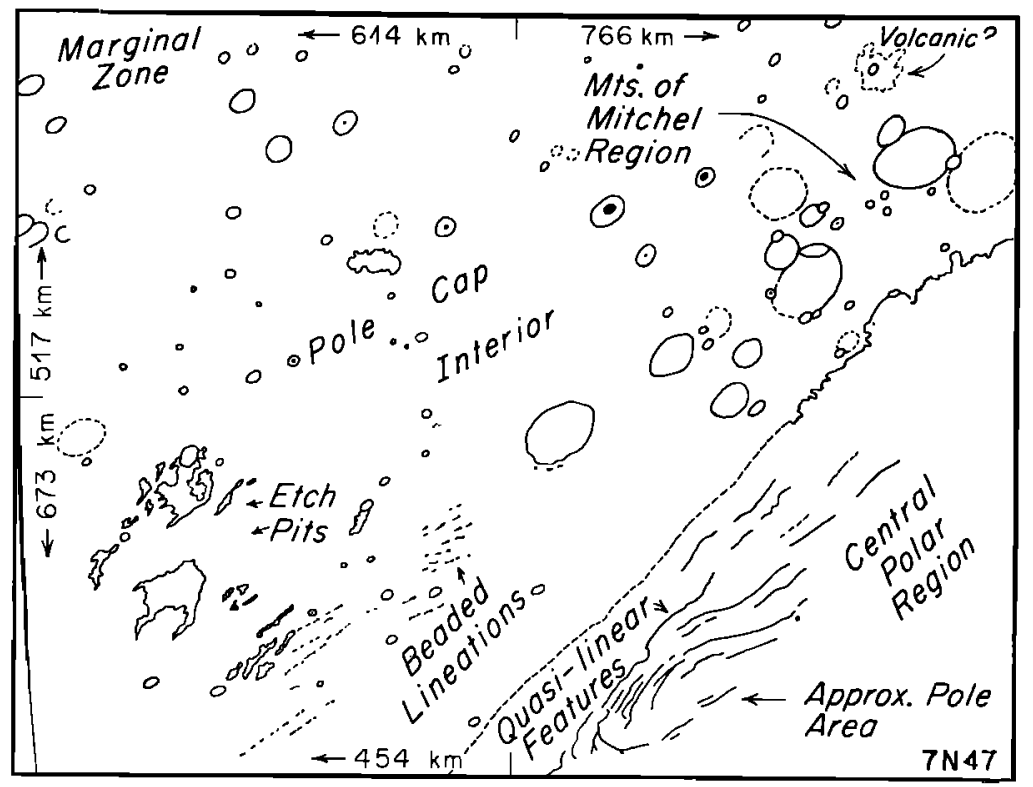

Fig. 5. Location sketch of regions and representative features appearing on $7 \mathrm{~N} 17$. 
irregular ridges bearing roughly northeast. In the upper left corner of the frame, an area of irregular hummocky terrain looks much like a lunar ejecta sheet, although it cannot be identified with any particular crater. Similar terrain is seen on a smaller scale around some of the larger craters of the pole-cap interior. It seems likely that a frost cover of irregular thickness and differences in texture here accentuates, to the point of visibility, minor topographic features probably present elsewhere on Mars, but hard to see.

Several parts of the polar cap interior show irregular areas of unusual luminance, 20 to $120 \mathrm{~km}$ across. These might be optically thick clouds, but they lack shadows and proper shape and structures. Leovy et al. [1971] are not convinced that they are clouds, so other explanations are sought. One might normally infer that the bright spots are higher areas favorably inclined to catch the sun. However, some lack a darker side away from the sun, and they, at least, are not high standing. Some white masses are streaky, and a highly irregular band of this type extends through the upper right part of $7 \mathrm{~N} 17$ and the central left part of $7 \mathrm{~N} 19$. This is not far from locations commonly cited for the Mountains of Mitchel (Figure 5), although geometrically the band does not match their shape.

\section{Central Polar Region}

Near the south pole is a distinctive sector (Figure 5). It has a paucity of craters, an assemblage of unusual quasi-parallel linear features, and a locally well-defined border lying between $78^{\circ}$ to $80^{\circ} \mathrm{S}$. This province appears to encircle the pole, but Mariner 7 near-encounter frames show clearly only the $165^{\circ}$ sector across the central meridian between $320^{\circ}$ and $125^{\circ} \mathrm{E}$.

The central polar region appears largely on $7 \mathrm{~N} 17$ and $7 \mathrm{~N} 19$. Its boundary in the central and eastern part of $7 \mathrm{~N} 19$ is an abrupt, irregular, crater-scalloped arc of perceptible vertical relief. Westward, the contact, less well defined, is drawn primarily on a contrast in crater abundance (Figure 5).

Only a few craters are seen in the central polar region, and most of them are indistinct. $A$ striking exception is the southern, or forefoot, crater of the pair comprising the 'giant's footstep' (7N19, 7N20). The forefoot crater lies within the central polar region, and the instep of the 'footprint' is the trace of the boundary described above. Other craters scalloping this boundary are also strongly expressed.

The most unusual central polar feature is an assemblage of quasi-linear markings, shown best in the south central part of $7 \mathrm{~N} 17$. These are close to and nearly centered on the pole (Figure 5). Individual markings have lengths up to $300 \mathrm{~km}$ and widths of $10 \mathrm{~km}$. They spread out eastward and converge westward with considerable curvature. The outermost has a sharp buckle at about $85^{\circ} \mathrm{S}, 30^{\circ} \mathrm{E}$. Some en echelon segmentation and a more confused pattern appear at the west end of the assemblage. Faint traces of these lineations swinging around the opposite side of the pole can be seen on some photo versions, and the pattern extends far eastward into $7 \mathrm{~N} 19$ for a total east-west length of $900 \mathrm{~km}$.

\section{Interpretations, Implications, and Specula- TIONS}

Differential Preservation of Frost, Marginal Zone.

Lingering of frost in crater bottoms in the outer marginal zone may be the result of protection from solar radiation and from winds and of a possibly greater initial thickness owing to larger vapor supply and wind drifting. Whatever the causes, preservation of frost in low areas is consistent with the analysis of Sagan and Pollack [1966, 1968] and the suggestion of O'Leary and Rea [1967] that the Mountains of Mitchel may really be the 'depressions of Mitchel.' Frames 7 N17 and 7N19 show several large craters, some seemingly irregular terrain, and a highly irregular bright band in the area cited as harboring the Mountains of Mitchel at about $73^{\circ} \mathrm{S}$, between longitudes $67^{\circ}$ and $93^{\circ} \mathrm{E}$ [Green, 1879; Slipher, 1962]. Locations are not accurate enough to support a direct correlation to any specific features, and the cap is still too far advanced to allow the Mitchel features to appear as separated forms. Insofar as frost preservation is a function of vapor-pressure relationships [Sagan and Pollack, 1966], it is consistent with the conclusion, now strongly supported by infrared radiometer [Neugebauer et al., 1969] and infrared spectrometer [Herr and Pimentel, 1969] observations, that the Martian polar caps are composed primarily of $\mathrm{CO}_{2}$. In the inner marginal zone, crater rims and 
other high-standing features range from thinly frosted to completely frost free. Frost on these features may have been initially thin for the converse of reasons suggested for thick frost in crater bottoms. Exposure to solar radiation and possibly some wind erosion have evidently further reduced or removed it. Evaporation of frost here appears to be strongly affected by surface inclination, for surfaces inclined toward the sun become frost free, whereas flat surfaces nearby remain frost covered. This is shown by the geometrical form of bare-ground patches that are parts of craters. Parts of high-standing features are also likely to become frost free because they have sun-facing slopes. Thus the small dark spots near the centers of some frostfloored craters in the marginal zone may be central peaks, not just aberrant bare spots on the crater floors.

These relationships suggest that solar radiation is a prime factor of frost wastage in the marginal zone. Coupled with the narrowness of the marginal zone, this assumption permits the inference that topographic slopes therein are surprisingly gentle. The argument is as follows. Assume an initial frost cover of uniform thickness, wastage of frost only by solar radiation, and the atmosphere playing no role. Under these conditions a slope such as the inner wall of a crater, inclined south at $5^{\circ}$, would experience nearly the same amount of insolation as a corresponding slope inclined $5^{\circ}$ northward but located $10^{\circ}$ farther south. Under the assumptions made, they should become frost free at about the same time, and the marginal zone of the polar cap should be about $10^{\circ}$ wide. In actual fact it is no more than $5^{\circ}$ wide. Thus, unless frost thickness and wastage in the marginal zone are strongly influenced by factors other than solar radiation, slopes of individual topographic features therein are likely to be something less than $5^{\circ}$.

\section{Frost Characteristics of Polar Cap Interior}

In the pole-cap interior, high features, such as crater rims and isolated knobs, are unusually bright compared with the surrounding surface, and both are brighter than the bottoms of most craters and 'etch pits.' The floors of these depressions are lighter than bare ground at the pole-cap margin, and the likelihood that they have only a thin or spatially intermittent frost cover is not consistent with the preservation of solid frost blankets on crater floors in the marginal zones. A likely alternative is that the frost on depression floors has a lower reflectivity than frost on crater rims or on intercrater surfaces. Frost in depressions in the waning phase of the pole-cap cycle may experience a history of sublimation and evaporation that gives it a different texture. Adiabatic compression and expansion of atmospheric gas moving over features of topographic relief may play a role in this textural differentiation.

The brightness of high-standing areas may be due to greater insolation on sun-facing slopes, possibly abetted by high-reflecting textures. White dots seen in the centers of a number of medium-size interior pole-cap craters may thus represent central peaks. Alternatively, they may represent frost accumulations of high reflectivity on the crater floor, especially in the instance of two or three craters with unusually large bright central markings (left center, 7 N19).

Some isolated, irregularly shaped patches and bands of higher than average luminance on the interior pole-cap surface (see $7 \mathrm{~N} 17$ for examples) appear to be high standing, but others, lacking a shaded side, may simply represent patches of frost, which for some local meteorological reason, have a highly reflective texture.

\section{Origin of 'Etch' Features}

Etch features have negative relief, highly angular outlines, and irregular shapes. Since nothing geometrically comparable is seen elsewhere on the Martian surface, etch features are assumed, as a working hypothesis, to exist wholly within the frost cover. If the elephant's footprint of $7 \mathrm{~N} 14$ is a frost-filled crater, it supports this hypothesis. Differential evaporation or some mechanical erosion process might produce etch features. Wind is a possible erosive agent, as it can scour in unusual fashion. Some etch pits are large $(90 \mathrm{~km}$ across) but no larger than eolian hollows on earth. Differential ablation might form the pits, owing to localized thin accumulations of dark-surface debris such as dust. This might account for the lower albedo of etch pit floors. Dollfus [1961] has commented on residual accumulation of dust on the polar frost through evaporation. Whatever the mechanism, the sharpness and angularity of etch features suggest undermining of a surficial slabby crust. 
Wind may have helped shape smaller features of the pole-cap interior. The beaded lineations (Figure 5, 7N15, 7N17) look wind molded, and fine detail on larger crater rims resembles scalloping and fluting by wind scour. Much of the polecap surface looks swept because of faint lineations and elongation of minor features, possibly produced through scour and drifting by wind.

\section{Quasi-Linear Markings of Central Polar Region}

The long quasi-linear markings of the central polar region are truely enigmatic. They are thought to be ground features, not clouds, owing to sharp boundaries, shape, shading, and lack of shadows. If the markings are grooves, the shading is proper, but if they are ridges, the sunny side is not bright. This could be the result of excessive evaporation or wind erosion on the sunny side, producing very thin or intermittently distributed frost, or of frost with an unuaually low reflective texture. The features might even be scarps, with a bright face and a band at the foot appearing dark for some unknown reason. A prolonged stare at $7 \mathrm{~N} 17$ with this concept in mind indeed makes the features look like scarps.

Whether troughs, ridges, or scarps, the matter of their genesis invites speculation. The features may be composed wholly of frost, snow, ice, or rock material. The possibility of dunes comes readily to mind, but these Martian features are less linear and less regular than most large terrestrial longitudinal dunes. The individual features with a width up to $10 \mathrm{~km}$ and a spacing up to $50 \mathrm{~km}$ are on a much larger scale than either terrestrial longitudinal or transverse dune ridges. The wind pattern required to produce dunes of this arrangement would have been roughly radial or concentric to the south pole, probably both if Bagnold [1941] is correct in his analysis of longitudinal dunes.

One intriguing line of thought is this. The phase of the precessional cycle of Mars is currently unfavorable to preservation of a south polar cap, owing to long hot summers. Even so, a small remnant of the cap a few degrees in diameter probably survives, centered at about $84^{\circ} \mathrm{S}, 330^{\circ} \mathrm{E}$, in most if not all years (Slipher [1962]; B. A. Smith, personal communication). In phases of the precessional cycle favoring short cool summers, it seems inevitable that a much larger mass of perennial ice lingered in the south pole region. This could mean that some part or parts of the south pole area have been occupied repeatedly by masses of ice, each lasting for a significant part of the 50,000-year precessional cycle. There is no way of knowing how long conditions on Mars have favored polar-cap formation, but it is a reasonable inference that the cumulative time of perennial ice-mass occupation of the south pole area may total millions, possibly billions, of years. The presence of such bodies during a cumulative temporal span of this magnitude might account for the unusual smoothness of the central polar region and the paucity and faintness of craters, as well as having something to do with development of the quasi-linear features. Conceivably, these features might be morainal in character, or they might be the edges of platy layers of remnant ice.

\section{Thickness and Permanence of Frost or Ice}

The thickness of frost composing the Martian polar caps has long been and remains a point of concern. Previous estimates range from $1 \mathrm{~mm}$ to 1 or 2 meters [de Vaucouleurs, 1954; Michaux, 1967; Glasstone, 1968].

Some craters of good size $(60-\mathrm{km}$ diameter) appear to be partly obscured by frost, and small craters appear less numerous within the polarcap area than on some other parts of Mars. Nonetheless, many craters show through the frost covering (Figure 3), some even as small as 1.4 and possibly $0.8 \mathrm{~km}$ in diameter, (see lower left quadrant of $7 \mathrm{~N} 16$ ). Thus frost thickness is locally great enough to modify crater appearance but in many places is not thick enough to blot the craters out. These relationships suggest significant variations in thickness, perhaps related to wind drifting.

The 'elephant's footprint' of 7N14 looks like a crater nearly filled with frost in which etch pits have subsequently been developed. If these and other etch features on the polar cap exist wholly within the frost layer, they suggest a thickness of at least tens of meters. Thus, solely from physical relationships seen on the TV photos, we conclude that localized maximum frost thicknesses are more likely to be on the order of tens of meters than millimeters or centimeters.

It is also possible that the polar regions may currently harbor local accumulations of old $\mathrm{CO}_{2}$ ice of even greater thickness. This material might be dirty enough to escape detection when the annual frost disappears, and it might have some- 
thing to do with etch pits and the quasi-linear marks of the central polar region.

\section{Quantitative Estimate of Solid $\mathrm{CO}_{2}$}

The condensation, evaporation, transport, and storage of $\mathrm{CO}_{2}$ throughout the 687-day annual period and the 50,000-year effective precessional cycle of Mars may follow one of several patterns, depending on total $\mathrm{CO}_{2}$ in the system. In order of increasing $\mathrm{CO}_{2}$ mass (values given in $\mathrm{g} / \mathrm{cm}^{-2}$ refer to the mass per $\mathrm{cm}^{2}$ column, averaged over the planet), the possibilities are:

1. Partial pressure of $\mathrm{CO}_{2}$ less than saturated vapor pressure at about $80^{\circ} \mathrm{K}$ : No $\mathrm{CO}_{2}$ frost condensation occurs anywhere at any time [Leighton and Murray, 1966, Figure 2].

2. Total mass greater than above but less than $\sim 10 \mathrm{~g} / \mathrm{cm}^{-2}$ : Annual $\mathrm{CO}_{2}$ frost condensation occurs at both poles, but no perennial frost exists at either pole except possibly in local windformed drifts [Leighton and Murray, 1966, p. 139].

3. Total mass between $\sim 10 \mathrm{~g} / \mathrm{cm}^{-2}$ and $\sim 100$ $\mathrm{g} / \mathrm{cm}^{-2}$ : A perennial $\mathrm{CO}_{2}$ frost cap normally exists at one pole, alternating between $\mathrm{S}$ and $\mathrm{N}$ through the precessional cycle. Local perennial deposits might occur at both poles owing to wind-formed drifts, dust blanketing, or both.

4. Total mass greater than $\sim 100 \mathrm{~g} / \mathrm{cm}^{-2}$ : Perennial $\mathrm{CO}_{2}$ frost caps would lie at both poles. Significant masses of $\mathrm{CO}_{2}$ might be effectively hidden under dust blankets.

The condition of Mars at present is either that of possibility 3 or possibility 4 . The mass limits given are approximate, based on a simple model that neglects atmospheric heat transport and cloud effects. The limit at about $100 \mathrm{~g} / \mathrm{cm}^{-2}$ derives from the difference in average insolation at the two poles owing to the orbital eccentricity. This effect limits interhemisphere $\mathrm{CO}_{2}$ transport to about $30 \mathrm{~g} / \mathrm{cm}^{-2}$ per martian annual cycle under present conditions.

Dust layers less than a few millimeters thick may enhance evaporation of $\mathrm{CO}_{2}$ by increased heat adsorption, but layers thicker than a few centimeters should diminish evaporation by insulation. Dust deposits on the cap could attain significant thicknesses in the course of the 50,000 year precessional cycle, an accumulation of only $1 \mu$ per year yielding $1 \mathrm{~cm}$ in $10^{4}$ years.

The actual situation on Mars remains uncertain, and a choice between conditions 3 and 4 is not yet possible. Several features seen in pole-cap pictures are interpretable in terms of windformed drifts, but evidence for massive perennial deposits related to the precessional cycle is less definite. The more prominent etch pits and the quasi-linear streaks near the south pole deserve consideration as possible indicators of such deposits. The topographic relief suggested by the larger etch pits seems too great to be accounted for by annual wind accumulation, but quantitative estimates of the relief are not available. Evidence of permanence of etch features or of the quasi-linear streaks near the pole, if such were forthcoming from Mariner 1971 data, would be most important to their interpretation.

\section{Comments Pertinent to the Mariner 1971 Mars Missions}

The 1971 flights to Mars are scheduled to arrive at about the beginning of southern summer and the initiation of northern winter. This means that the edge of the south ploar cap will have receded far beyond the position observed during the 1969 flyby, and the north polar cap will be in an initial phase of expansion. As now programmed both Missions A and B of the 1971 Mariner will provide TV and other instrumental coverage of the polar cap areas.

A stated aim of mission $B$ is to examine with care and detail the extramarginal and marginal zones of the south polar cap and to monitor changes and developments in these as the season advances. It will be particularly interesting to see if the features described in the outer and inner marginal zones and in the polar-cap interior actually develop one after the other in the succession inferred. Confirmation or modification of inferences drawn as to relationships between frost preservation, topography, and exposure to the sun would be important. Further evidence that frost is preferentially preserved in the lowest spots would be most valuable.

In addition to watching for signs of the polar collar in the extramarginal area, it would be desirable to inspect the seemingly craterless western part of $7 \mathrm{~N} 11$ to see if it was obscured by clouds or haze in 1969 . The polar margin is also one of the best places to watch for optically thick clouds.

Within the pole-cap interior, etch features should be carefully watched, as changes in their appearance could give an indication of their 
nature and origin. Lineations should be monitored, and temporal changes in surface features on the cap possibly related to wind action should be watched for. Changes in reflectivity independent of lighting conditions, if any are seen, would also be of interest.

Particular attention should be given to determining whether the quasi-linear features of the central polar region are ephemeral or permanent. Any data obtained on changes of appearance with the season, time of day, or other temporal conditions could throw light on their nature and origin. Finally, it will be extremely interesting to compare photographs of the same plot of ground in the frost-mantled and the frost-free states.

The south polar cap and environs provide unusually interesting areas for Mariner 1971 study. Meteorological conditions permitting, observations of the north polar cap should be just as interesting. It will be in a waxing phase, hence differences are to be anticipated; but similarities with south polar cap features would be significant, if found.

Acknowledgments. We are deeply indebted to all persons whose combined efforts made the Mariner 1969 flights to Mars a success. With respect to the series of four articles on Martian surface features published in this issue, we specifically acknowledge the valuable aid of the following: G. E. Danielson, S. A. Collins, J. J. van der Woude, T. C. Rindfleisch, J. A. Dunne, R. C. Dewar, and Patricia Conklin, all of Caltech and California Institute of Technology JPL. Our colleagues of the Mariner TV team, M. E. Davies, A. H. Herriman, N. H. Horowitz, C. B. Leovy, B. A. Smith, and A. T. Young have provided counsel and information.

The participation of three authors (Murray, Leighton, and Sharp) has been underwritten by the California Institute of Technology. Cutts has been partly supported by NASA-105-69836 and Soderblom by NGL-05-002-003.

\section{References}

Bagnold, R. A., The Physics of Blown Sand and Desert Dunes, 265 pp., Methuen, London, 1941. de Vaucouleurs, Gerard, The Planet Mars, (Engl. Transl.) 91 pp., Faber and Faber, London, 1954.

Dollfus, Audouin, Visual and photographic studies of planets at the Pic du Midi, in The Solar System, vol. 3, Planets and Satellites, edited by G. P. Kuiper and B. M. Middlehurst, chap. 15, pp. 534-571, University of Chicago Press, Chicago, 1961.

Glasstone, Samuel, The Book of Mars, 315 pp., U.S. Govt. Print. Office, 1968.

Green, N. E., Observations of Mars at Madeira, in August and September 1877, Mem. Roy. Astrom. Soc., 44, 123-140, 1879.

Herr, K. C., and G. C. Pimentel, Infrared absorption near three microns recorded over the polar cap of Mars, Science, 166 (3904), 496-499, 1969.

Leighton, R. B., and B. C. Murray, Behavior of carbon dioxide and other volatiles on Mars Science, 153 (3732), 136-144, 1966.

Leovy, C. B., B. A. Smith, A. T. Young, and R. B. Leighton, Mariner Mars 1969: Atmospheric results, J. Geophys. Res., 76, this issue, 1971.

Michaux, C. M., Handbook of the Physical Properties of the Planet Mars, 167 pp., NASA, SP. 3090, 1967.

Neugebauer, G., G. Münch, S. C. Chase, H. Hatzenbeler, E. Miner, and D. Schofield, Mariner 1969: Preliminary results of the infrared radiometer experiment: Science, 166 (3901), 98-99, 1969.

O'Leary, B. T., and D. G. Rea, Mars: Influence of topography on formation of temporary bright patches, Science, 155 (3760), 317-319, 1967.

Sagan, Carl, and J. B. Pollack, Elevation differences on Mars, Smithson. Inst. Astrophys. Observ. Spec. Rep. 224, 45 pp., 1966.

Sagan, Carl, and J. B. Pollack, Elevation differences on Mars, J. Geophys. Res., 7S, 1373-1387, 1968.

Slipher, E. C., The Photographic Story of Mars, 168 pp., Sky Publishing, Cambridge, Mass., 1962.

(Received August 10, 1970; revised September $7,1970$. 